\title{
AS PRÁTICAS DE AVALIAÇÃO DA APRENDIZAGEM NA CONCEPÇÃO DOS ALUNOS DO CURSO DE ADMINISTRAÇÃO DA UNIVERSIDADE ESTADUAL DO PARANÁ
}

\author{
LEARNING ASSESSMENT PRACTICES IN CONCEPTION OF THE \\ STUDENTS OF THE ADMINISTRATION COURSE AT THE STATE \\ UNIVERSITY OF PARANÁ
}

Cleverson Molinari Mello

Pós-Doutor em Educação pela Universidade Tuiuti do Paraná (UTP) Professor Adjunto da Universidade Estadual do Paraná (UNESPAR) cleverson.mello@unespar.edu.br

Pedro Leão da Costa Neto Doutor em Ciências Humanas na área de Filosofia pela Universidade de Varsóvia Professor adjunto da Universidade Tuiuti do Paraná (UTP) pedro.costa@utp.br

Resumo: A avaliação precisa ser objeto constante de análise para se saber se de fato ela está contribuindo no processo de ensino-aprendizagem e verificar se as práticas são condizentes com um processo avaliativo formativo. Some-se a complexidade do tema ainda mais por serem incipientes as contribuições no nível do ensino superior em comparação a educação básica. Para colaborar com o debate, o presente estudo foi realizado no Curso de Administração da Universidade Estadual do Paraná (UNESPAR), Campus de Paranaguá, constituindo-se em duas etapas. A primeira através da análise do projeto político-pedagógico e dos planos de ensino do curso. A segunda através de uma pesquisa com os alunos dos últimos anos. O objetivo da investigação foi analisar se o processo de avaliação da aprendizagem nesse curso está cumprindo o seu papel pedagógico ou somente serve como um instrumento tradicional. Desta forma, elaboramos a seguinte questão: Qual a relação existente entre o que é proposto no PPC (UNESPAR, 2020), nos planos de ensino e a percepção dos alunos com relação as práticas avaliativas? A análise dos dados foi realizada através da técnica de análise de conteúdo de Bardin (2016). As conclusões indicam que o PPC (UNESPAR, 2020) está um pouco distante da ideia de avaliação formativa. Por sua vez, os planos de ensino seguem na mesma direção do PPC (UNESPAR, 2020), sendo confirmado pelos próprios alunos na pesquisa.

Palavras-chave: Educação superior. Aprendizagem. Avaliação.

\begin{abstract}
The evaluation needs to be a constant object of analysis in order to know if in fact it is contributing to the teaching-learning process and to verify if the practices are consistent with a formative evaluation process. Add to the complexity of the theme even more because the contributions at the level of higher education compared to basic education are incipient. To collaborate with the debate, this study was carried out in the Administration Course of the State University of Paraná - UNESPAR - Campus of Paranaguá, consisting of two stages. The first through the analysis of the political-pedagogical project and the teaching plans of the course. The second through a survey of students in recent years. The objective of the investigation was to analyze whether the learning assessment processes in this course are fulfilling their pedagogical role or only serve as a traditional instrument. Thus, we ask the following question: What is the relationship between what is proposed in the PPC (UNESPAR, 2020), in the teaching plans amidst the students' perception regarding the evaluative practices? Data analysis was performed using Bardin's content analysis technique (2016). The conclusions indicate that the PPC (UNESPAR, 2020) is a little distant from the idea of formative evaluation. In turn, the teaching plans follow the same direction as the PPC (UNESPAR, 2020), being confirmed by the students themselves in the research.
\end{abstract}

Keywords: Higher education. Learning. Evaluation.

Para citar - (ABNT NBR 6023:2018)

MELLO, Cleverson Molinari; COSTA NETO, Pedro Leão da. As práticas de avaliação da aprendizagem na concepção dos alunos do curso de administração da universidade estadual do Paraná. Eccos - Revista Cientifica, São Paulo, n. 55, p. 1-14, e18871, out./dez. 2020. Disponível em: https://doi.org/10.5585/eccos.n55.18871. 


\section{Introdução}

A maneira como o professor vê o mundo e fundamenta seus conceitos sobre a educação determina sua relação com a avaliação. Some-se a isso, professores das áreas das Ciências exatas e sociais aplicadas, por exemplo, que não tiveram em suas formações uma sólida preparação pedagógica. Nesta perspectiva, a avaliação, em sua grande maioria, poderá ser considerada apenas no nível tradicional, somatório e classificatório.

Se, por um lado, temos esse tipo de avaliação limitada e, por que não, excludente; por outro, temos a avaliação formativa que proporciona a oportunidade de todos aprenderem, por isso democrática. Mesmo que em ritmos diferenciados, por isso justa. E desde que assegurados os recursos e meios necessários, por isso coerente.

É através da relação harmoniosa e consciente entre professor e aluno que a avaliação formativa consegue absorver as informações necessárias para se atingir o conhecimento constante. Independente da terminologia entre os diversos autores, dialógica, mediadora, cidadã ou emancipatória, a avaliação formativa busca ser democrática, justa e coerente. Se para Freire (1997) essa avaliação indica o caminho da transformação e beneficia os envolvidos, para Hoffman (1994) constitui uma ação reflexiva e desafiadora entre professor e estudante, estimulando a produção do conhecimento. Uma reflexão profunda sobre as formas de compreensão do aluno sobre o objeto do conhecimento.

O presente estudo procura evidenciar a relação entre o que é proposto no PPC (UNESPAR, 2020), nos planos de ensino e a percepção dos alunos com relação às práticas avaliativas em uma universidade pública. Trata-se, pois, de provocar reflexões sobre a importância da avaliação formativa como forma de analisar a aprendizagem, elaborar estratégias de superação de dificuldades e de proporcionar um retorno aos alunos.

\section{Avaliação formativa}

Adequar os processos de formação às características dos alunos, levando em conta as especificidades individuais, impõe ao professor no momento da avaliação inúmeros desafios a serem superados.

Nesse cenário, eis que surge a proposta da avaliação formativa: que longe de ser um mero instrumento somatório, permite construir, reconstruir e dimensionar o percurso da aprendizagem através da participação de ambos os atores envolvidos. Logo, a avaliação deve ser pensada como um processo contínuo e não somente um momento único. Na concepção de 
Hoffman (1998) a avaliação deixa de ser um momento terminal para se transformar em uma procura incessante das limitações do aluno.

O processo de aprendizagem, a análise das dificuldades dos alunos, a busca por soluções e o realinhamento pedagógico em sala de aula, faz da avaliação formativa um importante instrumento, contínuo e interativo, na construção do conhecimento.

A avalição formativa possibilita, num primeiro momento, diagnosticar o nível de conhecimento do aluno permitindo escolher, desta forma, o direcionamento mais viável no desenvolvimento do processo de aprendizagem. Fica evidente, pois, que a avaliação formativa, já na sua fase inicial torna-se inclusiva; e permite ao professor poder buscar outras ferramentas de avaliação para oportunizar a todos os alunos o ato de aprender. No entanto, segundo Perrenoud (1999), não basta ser adepto da ideia de uma avaliação formativa; é necessário, também, que o professor tenha os meios para construir seu próprio sistema com o intuito de observar, interpretar e intervir. Ainda segundo Perrenoud (1999), o diagnóstico é inútil se não der lugar a uma ação apropriada, ou seja, uma avaliação acompanhada de uma intervenção diferenciada com o que isso supõe em termo de ensino, de organização dos horários, de organização de grupos-aula, até mesmo de transformações radicais de estruturas escolares.

Se num primeiro momento a avaliação formativa permite um diagnóstico do nível de conhecimento do aluno, num segundo momento, durante o processo de ensino-aprendizagem, a interação contínua possibilita interpretar os percalços e assim, adequar e realinhar o processo com base nas vitórias e fracassos. Mas, para tanto, o professor deverá propor modelos de ação e principalmente de renúncia: do que ele é, faz e crê. O que, de certa forma, não é nada fácil. Segundo Hadji (2001) para a avaliação ser de fato formativa, não é necessário seguir um modelo metodológico pré-definido, contando, pois, com a boa intenção do professor em tornar a avalição formativa.

Se superado esses dois primeiros momentos, a avaliação formativa, após um curto período, poderá ser reavaliada e reordenada. E caso tudo ocorra sem maiores problemas e após um período mais longo, poderá ser reorganizada a partir das especificidades dos alunos se for o caso. Para Hadji (2001) uma avaliação sem modificações das práticas pedagógicas do professor tem chances reduzidas. Daí a necessidade de se compreender de forma plena a avaliação formativa enquanto ferramenta flexível.

Portanto, destaca-se as seguintes características da avaliação formativa:

- É responsável por uma considerável melhoria no processo ensino-aprendizagem;

- Proporciona um olhar diferenciado ao considerar a subjetividade dos atores envolvidos; 
- Trata-se de um processo flexível, contínuo e adaptável;

- Fomenta a reflexão, estimula a ação renovadora e a cooperação entre os atores envolvidos;

- Tem uma dimensão emancipatória

\section{Metodologia}

Na análise documental foram utilizados o PPC (UNESPAR, 2020) e os planos de ensino do curso. Quanto à pesquisa de campo, foi realizado um questionário com uma questão aberta tendo como público alvo 43 (quarenta e três) alunos das diferentes turmas do quarto ano do curso de Administração da Universidade Estadual do Paraná (UNESPAR), Campus de Paranaguá. Os dados obtidos através dos questionários foram analisados e interpretados através da técnica de análise de conteúdo. Sendo assim, por meio das informações contidas nos questionários, buscou-se localizar aquelas em que os alunos apontassem sua percepção sobre as avaliações.

\section{Plano político-pedagógico e planos de ensino}

Abaixo o que consta no PPC (UNESPAR, 2020) do curso.

Quadro 1 - Avaliação da aprendizagem contido no PCC do curso de administração Avaliação de aprendizagem

Sistemas de avaliação do curso

O processo de avaliação é tido no curso como uma ferramenta para identificar pontos fracos que se apresentem no processo ensino-aprendizagem em busca de melhoria contínua, mantendo a avaliação formal estabelecida nos regimentos institucionais.

A avaliação, portanto, não fica restrita ao momento da realização das provas e testes, mas a um processo contínuo e que ocorre dia após dia, visando à correção de erros e encaminhando o aluno para aquisição dos objetivos previstos.

Nesse sentido, portanto, a avaliação não ocorre somente nas atividades de ensino previstas nas disciplinas dispostas na matriz curricular, mas também nas atividades de pesquisa, nas quais os estudantes participam com seus orientadores, resultando na melhoria e interesse com a crescente evolução nas publicações científicas e, ainda, nas atividades de extensão universitária, criando uma cultura extensionista com um número cada vez maior de acadêmicos participando dos projetos desenvolvidos pelo curso.

Fonte: Os autores.

Observa-se que o discurso do PPC (UNESPAR, 2020) está um pouco distante da ideia de avaliação formativa. Expressões do tipo "identificar pontos fracos”, "melhoria contínua”, 
“avaliação formal”, “correção de erros”, remetem mais ao ambiente corporativo e focam as práticas empresariais para a qual o curso é direcionado.

Errar dentro de um processo de apropriação dos saberes, não pode ser compreendido como sinônimo de não acertar. $\mathrm{O}$ ato de errar é tão somente uma das etapas no processo em direção ao domínio do que ainda não foi assimilado. Quando se considera apenas o errar como algo ruim a ser eliminado, reduz-se este importante indicador da aprendizagem a uma única dimensão classificatória. A pura e simples "correção de erros" ou "eliminação de erros" pode desqualificar o aluno, jogando toda a responsabilidade do conteúdo não assimilado sobre suas costas, diminuindo suas notas e consequentemente levando a repetição de ano. Portanto, em vez de combatidos, os erros podem ser ressignificados (PERRENOUD, 2000). Mas será preciso um esforço por parte do professor no sentido de compreender e superar. De perceber. De ler nas entrelinhas o que, de fato, aquele erro quer dizer. Compreender, superar e perceber o significado pode proporcionar intervenções pedagógicas importantes no processo de avaliação.

Um ponto interessante que chama a atenção e que é encontrado no PPC (UNESPAR, 2020) é a vinculação da avaliação em atividades de pesquisa e extensão, fazendo, desta forma, com que avaliação vá para além da universidade. Tal encaminhamento lembra a avaliação formativa em sua dimensão emancipatória que na concepção de Abramowicz (2010) ultrapassa os muros da instituição, vivendo uma práxis criadora.

A seguir reproduzimos, os procedimentos de avaliação nos planos de ensino. 
Quadro 2 - Avaliação da aprendizagem contido nos planos de ensino

\begin{tabular}{|c|c|}
\hline Disciplina & Critérios de Avaliação \\
\hline Metodologia de Pesquisa & $\begin{array}{l}\text { As avaliações ocorrerão através de trabalhos escritos, apresentação de seminários } \\
\text { e outros meios, cuja escolha fica à cargo da professora. A avaliação final será } \\
\text { realizada através da entrega do projeto final de pesquisa }\end{array}$ \\
\hline Sociologia & $\begin{array}{l}\text { Trabalhos em grupo: Estudos de caso. Atividades avaliativas em sala de aula. Participação e } \\
\text { frequência. Prova bimestral. }\end{array}$ \\
\hline Responsabilidade Social & $\begin{array}{l}\text { Avaliação por provas escritas, trabalhos, apresentações e desempenho em sala de aula } \\
\text { Avaliações de projetos }\end{array}$ \\
\hline T.G.A. & $\begin{array}{l}\text { Trabalhos em grupo em sala de aula. Apresentação de seminários. } \\
\text { Participação e frequência. Prova bimestral. }\end{array}$ \\
\hline Economia & $\begin{array}{l}\text { Serão efetuadas } 4 \text { provas bimestrais e } 4 \text { trabalhos bimestrais com peso de } 50 \% \\
\text { respectivamente. Periodicamente será cobrado dos alunos trabalhos práticos e/ou } \\
\text { resolução de exercícios em sala de aula, os quais a pontuação será acrescida a média } \\
\text { bimestral, sendo que não será permitido a realização desses trabalhos caso não esteja } \\
\text { presente em sala de aula. }\end{array}$ \\
\hline Materiais & $\begin{array}{l}\text { As avaliações ocorrerão através de trabalhos escritos, apresentação de seminários e } \\
\text { outros meios, cuja escolha fica à cargo da professora. A avaliação final será realizada } \\
\text { através da entrega do projeto final de pesquisa. }\end{array}$ \\
\hline Recursos Humanos & Atividades avaliativas em aula (20\%). Estudo de caso em grupo (20\%). Prova Bimestral (60\%) \\
\hline Marketing & Fichamentos e estudos de caso (40\%). Avaliação bimestral (60\%). \\
\hline Produção & $\begin{array}{l}\text { A síntese da avaliação } \\
\text { será feita em quatro notas parciais em que serão levados em consideração os exercícios } \\
\text { propostos nos encontros semanais, trabalhos pré definidos e quatro prova escrita. } \\
\text { Será realizada de maneira somativa, sendo de } 0 \text { a } 70 \% \text { para a avaliação escrita e de } 0 \text { a } 40 \% \\
\text { em trabalhos práticos e interdisciplinares. }\end{array}$ \\
\hline Sistemas de Informação & $\begin{array}{l}\text { Trabalhos: } 10,0 \\
\text { Prova Bimestral:10,0 } \\
\text { Média: T.I + P.B/2 } \\
\end{array}$ \\
\hline Jogos de Empresas & $\begin{array}{l}\text { Freqüência, participação em sala de aula, provas e trabalhos individuais, em equipe e } \\
\text { resultado das ações }\end{array}$ \\
\hline Gestão da Qualidade & $\begin{array}{l}\text { Trabalho em grupo em sala de aula (20\%) } \\
\text { Prova bimestral (70\%). } \\
\text { Presença em aula e participação nas discussões (10\%) } \\
\end{array}$ \\
\hline A.F.O. & $\begin{array}{l}\text { Trabalhos em grupo: Estudos de caso (20\%). } \\
\text { Atividades avaliativas em sala de aula (20\%) } \\
\text { Participação e frequência; (05\%) } \\
\text { Prova bimestral (55\%). }\end{array}$ \\
\hline Estratégia & $\begin{array}{l}\text { Trabalho em grupo: Estudos de caso empresarial }(20 \%) \text {. } \\
\text { Atividades avaliativas em sala de aula (30\%) } \\
\text { Prova bimestral (50\%). }\end{array}$ \\
\hline
\end{tabular}

Fonte: Os autores.

Os planos de ensino, em sua grande maioria, seguem a linha do PPC (UNESPAR, 2020) do curso quando aparecem as expressões "avaliação formal" e "correção de erros".

Apesar da maioria dos planos de ensino não utilizarem apenas a prova escrita, mas também outros procedimentos avaliativos, a prova escrita aparece com peso maior que os demais procedimentos avaliativos, reforçando ainda mais seu caráter tradicional. Na análise foi verificado que na disciplina de Sistemas de Informação é utilizada a média aritmética como critério para se chegar a nota final do bimestre. 
Consta que,

A avaliação não ocorre somente nas atividades de ensino previstas nas disciplinas dispostas na matriz curricular, mas também nas atividades de pesquisa, nas quais os estudantes participam com seus orientadores, resultando na melhoria e interesse com a crescente evolução nas publicações científicas e, ainda, nas atividades de extensão universitária, criando uma cultura extensionista. (UNESPAR, 2020, p. 46).

No entanto não é explicitado nos Planos de Ensino, como se dará a avaliação nas atividades de Pesquisa e Extensão. Quais os procedimentos e parâmetros para tal. A seguir, a pesquisa e análise da percepção dos alunos com relação às avaliações.

A análise empírica foi baseada em uma pesquisa aplicada para 43 (quarenta e três) alunos de diferentes turmas do quarto ano. Para tanto, foi feita a seguinte pergunta:

- Você considera que as avaliações promovem uma perfeita análise de seu desenvolvimento, colaborando com seu conhecimento?

A seguir reproduzimos a totalidade das respostas:

Entrevista 01: Não são totalmente eficazes;

Entrevista 02: Acredito que seja apenas um instrumento tradicional;

Entrevista 03: Servem somente como instrumento tradicional. Causa uma tensão, principalmente quando as avaliações de todas as disciplinas caem muito próximas umas das outras;

Entrevista 04: Concordo com as avaliações, desde que sejam bem alinhadas, utilizando vários métodos de aplicação, além das provas;

Entrevista 05: Não promovem uma análise $100 \%$ efetiva do desenvolvimento $e$ conhecimento;

Entrevista 06: Instrumento de caráter classificatório e somatório;

Entrevista 07: As avaliações são essenciais para nos prepararmos melhor e obtermos ótimos conhecimentos. Poderia melhorar em relação a algumas matérias, pois tem conteúdos importantes que nem sempre são cobrados em prova;

Entrevista 08: Servem apenas como um instrumento tradicional de caráter classificatório, pois apenas se estuda para obter a nota e muitas vezes o conhecimento não é absorvido. As avaliações podem contribuir para um quadro de ansiedade uma vez que o aluno se sente pressionado;

Entrevista 09: Serve apenas como instrumento classificatório e somatório. Por muitas vezes me sinto pressionada a decorar o conteúdo do que o absorver;

Entrevista 10: Elas são ferramentas importantes para avaliar o conhecimento, porém, outros métodos podem trazer uma análise melhor do desenvolvimento. Em avaliações 
escritas sempre fico nervoso e ansioso. Acaba me dando um branco. Trabalhos em grupo, discussões no geral, consigo absorver e entender muito mais;

Entrevista 11: As avaliações feitas agregam bastante conhecimento, pois, aborda tudo o que foi discutido durante as aulas;

Entrevista 12: Olhando no geral, elas são satisfatórias, pois contribuem para nosso conhecimento e formação;

Entrevista 13: Não mensura o conhecimento adequadamente;

Entrevista 14: A grande maioria das avaliações é de caráter classificatória e somatória, ou seja, não determina o nível de absorção e conhecimento desenvolvido;

Entrevista 15: As avaliações são muito bem aplicadas, algumas com um grau de dificuldade maior do que outras. Seria melhor para os alunos se as provas não fossem realizadas em apenas uma semana;

Entrevista 16: Sim. A avaliação colabora com o conhecimento;

Entrevista 17: As avaliações aplicadas em sala de aula são equivalentes as experiências vividas em uma organização;

Entrevista 18: As avaliações são essenciais. São agregadas ao meu desenvolvimento e conhecimento;

Entrevista 19: Muitas vezes as avaliações são feitas com questões de concursos, onde não agregam ao nosso dia-a-dia. Torna-se algo maçante e de caráter classificatório. São ótimas quando envolvem questões e matérias discutidas na rotina, conforme a relação entre a matéria e a prática;

Entrevista 20: Sugiro uma avaliação por parte do colegiado para rever a metodologia de alguns professores;

Entrevista 21: Muitas vezes servem apenas como instrumento tradicional;

Entrevista 22: Foram poucas avaliações que eu considerei que estava agregando ao meu conhecimento;

Entrevista 23: As avaliações servem apenas como um somatório onde causa pressão psicológica nos alunos podendo afetar seu desempenho;

Entrevista 24: Acredito que em grande maioria, elas só servem como um instrumento tradicional de caráter classificatório e somatório. Em apenas algumas aplicações com dinâmicas diferenciadas como aplicação de seminários ou atividades avaliadas em grupos acabam agregando conhecimento;

Entrevista 25: É um instrumento necessário, porém a forma como vem sendo aplicado deve ser repensado;

Entrevista 26: Muitos professores se dedicam a apresentar outros meios de avaliação além da prova, dando oportunidades aos alunos de terem outras experiências. Mas, quando a avaliação é apenas prova, me sinto muito insatisfeita e muitas vezes insegura; 
Entrevista 27: Isso varia de acordo com o professor, mas grande parte das vezes a avaliação é de caráter classificatório;

Entrevista 28: É claro que existe matérias com um tom mais teórico e acaba existindo uma dificuldade para variar nas avaliações, mas geralmente acaba sendo um instrumento classificatório e somatório;

Entrevista 29: Minha opinião é que em forma de seminário, onde posso explicar e desenvolver o conhecimento, me sinto mais segura;

Entrevista 30: Geralmente classificatório, apenas o decorar;

Entrevista 31: Dependendo do tipo e como foi formulada, podem auxiliar no desenvolvimento;

Entrevista 32: Conteúdos maçantes ou excesso de avaliações num curto espaço de tempo não é capaz de demonstrar conhecimento, mas sim a capacidade de decorar;

Entrevista 33: Na maioria das vezes apenas somatório e classificatório. A avaliação feita no dia-a-dia é muito mais proveitosa. Já a avaliação onde é cobrado o conteúdo de um bimestre todo, pode até causar algum transtorno;

Entrevista 34: Varia conforme o professor. As avaliações me causam nervosismo;

Entrevista 35: De forma parcial, as avaliações têm sim o objetivo de promover uma análise do meu desenvolvimento;

Entrevista 36: É um instrumento tradicional que na minha opinião coloca pressão no aluno;

Entrevista 37: Acredito que metade das disciplinas realizam uma perfeita análise, sendo as matérias exatas mais complexas em questões de avaliação;

Entrevista 38: Promovem análise de desenvolvimento;

Entrevista 39: As avaliações colaboram com o meu conhecimento;

Entrevista 40: De modo geral, é possível afirmar que as avaliações serviram sim como análise de desenvolvimento;

Entrevista 41: As avaliações sim conseguem promover uma perfeita análise do nosso desenvolvimento. Para os alunos mais tímidos, as avaliações escritas são o melhor meio de avaliação;

Entrevista 42: Fico bastante tensa e tenho baixo rendimento em questões de múltipla escolha;

Entrevista 43: Servem apenas como instrumento tradicional e robótico para classificar suposto conhecimento.

Após análise, organização dos temas, codificação, classificação e categorização, segue: 
Quadro 3 - Você considera que as avaliações promovem uma perfeita análise de seu desenvolvimento, colaborando com seu conhecimento?

Categoria: Apesar das avaliações contribuirem para o conhecimento elas são tradicionais, classificatórias, somatórias e provocam tensão.

\begin{tabular}{|c|c|}
\hline \multicolumn{2}{|r|}{$\begin{array}{l}\text { Categoria: Apesar das avaliações contribuirem para o conhecimento elas são tradicionais, } \\
\text { classificatórias, somatórias e provocam tensão. }\end{array}$} \\
\hline Definiç̧ão: & $\begin{array}{l}\text { As avaliações são ferramentas importantes para avaliar o conhecimento. } \\
\text { Acabam sendo um instrumento classificatório, } \\
\text { somatório e classificatório. Provocam tensão. }\end{array}$ \\
\hline Temas & Exemplos de verbalizações \\
\hline $\begin{array}{l}\text { Tradicionais } \\
\text { Somatórias } \\
\text { Classificatórias }\end{array}$ & $\begin{array}{l}\text { E2: Acredito que seja apenas um instrumento tradicional. } \\
\text { E3: Servem somente como instrumento tradicional. } \\
\text { E6: Instrumento de caráter classificatório e somatório. } \\
\text { E8: Servem apenas como um instrumento tradicional de caráter classificatório. } \\
\text { E9: Serve apenas como instrumento classifiacatório e somatório. } \\
\text { E14: A grande maioria das avaliações é de caratér classificatória e somatória. } \\
\text { E19: Torna-se algo maçante e de caráter classificatório. } \\
\text { E21: Muitas vezes servem apenas como instrumento tradicional. } \\
\text { E24: Acredito que em grande maioria, elas só servem como um instrumento tradicional } \\
\quad \text { de caráter classificatório e somatório. } \\
\text { E27: Isso varia de acordo com o professor, mas grande parte das vezes a avaliação } \\
\quad \text { é de caráter classificatório. } \\
\text { E28: Mas geralmente acaba sendo um instrumento classificatório e somatório. } \\
\text { E30: Geralmente classificatório, apenas o decorar; } \\
\text { E33: Na maioria das vezes apenas somatório e classificatório; } \\
\text { E36: É um instrumento tradicional; } \\
\text { E43: Servem apenas como instrumento tradicional. }\end{array}$ \\
\hline $\begin{array}{l}\text { Contribuem } \\
\text { para o } \\
\text { conhecimento }\end{array}$ & $\begin{array}{l}\text { E7: As avaliações são essencias para nos preparmos e obtermos ótimos conhecimentos. } \\
\text { E10: Elas são ferrametas importantes para avaliar o conhecimento. } \\
\text { E11: As avaliações feitas agregam bastante conhecimento. } \\
\text { E12: Contribuem para nosso conhecimento e formação. } \\
\text { E15: As avaliações são muito bem aplicadas. } \\
\text { E16: A avaliação colabora com o conhecimento. } \\
\text { E17: As avaliações aplicadas em sala de aula são equivalentes as experiências vividas } \\
\text { em uma organização. } \\
\text { E18: As avaliações são essenciais. } \\
\text { E25: É um instrumento necessário. } \\
\text { E31: Podem auxiliar no desenvolvimento. } \\
\text { E35: Tem sim o objetivo de promover uma análise do meu desenvolvimento. } \\
\text { E37: Realizam uma perfeita análise. } \\
\text { E38: Promovem análise de desenvolvimento. } \\
\text { E39: As avaliações colaboram como o meu conhecimento. } \\
\text { E40: É possível afirmar que as avaliações serviram sim como análise de desenvolvimento. } \\
\text { E41: As avaliações sim conseguem promover uma perfeita análise do nosso desenvolvimento. }\end{array}$ \\
\hline $\begin{array}{l}\text { Provocam } \\
\text { tensão }\end{array}$ & $\begin{array}{l}\text { E3: Causa uma tensão, principalmente quando as avaliações de todas as disciplinas caem } \\
\text { muito próximas umas das outras. } \\
\text { E9: Por muitas vezes me sinto pressionada a decorar o conteúdo do que o absorver. } \\
\text { E10: Em avaliações escritas sempre fico nersoso e ansioso. Acaba me dando um branco. } \\
\text { E23: Causa pressão psicológica nos alunos podendo afetar seu desempenho. } \\
\text { E26: Quando a avaliação é apenas prova, me sinto muito insatisfeita e muitas vezes insegura. } \\
\text { E33: Já a avaliação onde é cobrado o conteúdo de um bimestre todo, } \\
\text { pode até causar algum transtorno. } \\
\text { E34: As avaliações me causam nervosismo. } \\
\text { E36: Coloca pressão nos alunos. } \\
\text { E42: Fico bastante tensa e tenho baixo rendimento em questões de múltipla escolha. }\end{array}$ \\
\hline
\end{tabular}

Fonte: Os autores. 
Os alunos de um modo geral consideram que apesar das avaliações contribuírem no processo de conhecimento elas são tradicionais, classificatórios, somatórias e provocam tensão.

A avaliação é parte fundamental do processo de ensino-aprendizagem além de condição estratégica enquanto elemento estrutural nos processos educacionais. Logo, seu papel é extremamente importante indo para além dos muros do ambiente escolar, desta forma, não podendo ser considerada um fim em si mesma. Os referenciais proporcionados ao detectar os pontos geradores do mau rendimento dos alunos, nas avaliações, servem como base para as mudanças pedagógicas necessárias no dia a dia; para assim melhorar o desempenho dos alunos. Para Vasconcellos (2007) a avaliação é um processo que sugere reflexão sobre o aprendizado para compreender os avanços e retrocessos. Para o autor, a avaliação possibilita uma tomada de decisão sobre o que e como sobrepujar os desafios existentes.

A contribuição da avaliação no processo ensino-aprendizagem parece estar claro para os alunos ficando explícito nas falas. “As avaliações são essenciais para nos prepararmos melhor e obtermos ótimos conhecimentos" (E07). "Elas são ferramentas importantes para avaliar o conhecimento" (E10). "As avaliações feitas agregam bastante conhecimento, pois, aborda tudo o que foi discutido durante as aulas" (E11).

Expressões como “essenciais”, “importantes”, “agregam”, são constantes no relato dos alunos. No entanto, a construção do conhecimento requer um esforço tanto dos professores, quanto dos alunos avaliados. Nesse contexto, ambos são imprescindíveis na busca por soluções e na melhoria do desenvolvimento da aprendizagem. A compreensão por parte dos alunos de que a avaliação é um processo natural e importante, e que ocorre para que o professor tenha o conhecimento do que foi assimilado, é um primeiro passo para que ambos compreendam, se, de fato, as metodologias de ensino estão surtindo os resultados desejados.

Para Saul (2008) a avaliação não é um ato imparcial, pois denota diferentes práticas e significados e até mesmo do próprio entendimento acerca da educação. Desta forma, é necessário um esforço maior por parte de professores no sentido de investir na formação pedagógica. Segundo Vasconcellos (2007) a avaliação dialético-libertadora exige uma modificação de atitude por parte do professor, investindo energia e potencialidade; não no controle acerca daquilo que foi transmitido, mas da aprendizagem do aluno.

Tais encaminhamentos podem colaborar no sentido de se evitar, por exemplo, que a avalição se torne um meio de exclusão do aluno. "Em avaliações escritas sempre fico nervoso e ansioso. Acaba me dando um branco" (E.10). "As avaliações me causam nervosismo" (E34). "Fico bastante tensa e tenho baixo rendimento em questões de múltipla escolha" (E42). Na concepção de Moraes (2011) os instrumentos de avaliação são capazes de coletar informações 
imprescindíveis, prevalecendo a prova, que possui aspectos positivos e negativos que são definidos a partir do que o professor faz com o resultado. "Muitas vezes as avaliações são feitas com questões de concursos, onde não agregam ao nosso dia-a-dia. Torna-se algo maçante e de caráter classificatório" (E19). "Foram poucas avaliações que eu considerei que estava agregando ao meu conhecimento" (E22). "Em apenas algumas aplicações com dinâmicas diferenciadas como aplicação de seminários ou atividades avaliadas em grupos acabam agregando conhecimento" (E24). "Muitos professores se dedicam a apresentar outros meios de avaliação além da prova, dando oportunidades aos alunos de terem outras experiências. Mas, quando a avaliação é apenas prova, me sinto muito insatisfeita e muitas vezes insegura" (E26).

Segundo Perrenoud (1999), tradicionalmente a avaliação é utilizada em âmbito escolar para classificar os alunos, ou seja, por meio das hierarquias de excelência estes ocupam uma determinada posição perante a um grupo, desconsiderando a qualidade do conteúdo de seus conhecimentos e competências.

Para Luckesi (2008), as práticas educativas têm apontado três procedimentos: medida do aproveitamento escolar, transformação desta medida em nota, e utilização desta nota para classificação. Segundo o autor, tais procedimentos não chegam a efetivar uma avaliação efetiva. "Não são totalmente eficazes" (E01). "Instrumento de caráter classificatório e somatório" (E06). "Servem apenas como um instrumento tradicional de caráter classificatório, pois apenas se estuda para obter a nota e muitas vezes o conhecimento não é absorvido" (E08). "Não mensura o conhecimento adequadamente" (E13). Para Perrenoud (1999) nenhum médico se preocupa em classificar seus pacientes, do menos doente ao mais gravemente atingido. Nem mesmo pensa em detalhes em lhes administrar um tratamento coletivo. Segundo o autor, o médico esforça-se para determinar, para cada um deles, um diagnóstico individualizado, estabelecendo uma ação terapêutica sob medida.

\section{Considerações finais}

O estudo permitiu identificar que as práticas avaliativas desenvolvidas no âmbito do curso de Administração da Universidade Estadual do Paraná (UNESPAR), Campus Paranaguá, estão muito aquém de uma avaliação formativa. Por outro lado, foi possível perceber que no PPC (UNESPAR, 2020) consta uma tentativa de avaliação em uma dimensão emancipatória, quando da vinculação da avaliação em atividades de pesquisa e extensão, apesar de não ser 
explicitado, nem no PPC (UNESPAR, 2020), nem nos planos de ensino, de que forma se dará tais encaminhamentos.

Com base nos relatos dos alunos, acreditamos que será preciso o curso repensar os processos de avaliação, tendo em vista, a predominância das expressões tradicional, somatória e classificatória. Some-se isso ao número considerável de alunos que considera uma pressão muito grande que as avaliações impõem psicologicamente. Sem contar, é claro, apesar de outros métodos avaliativas, ser a prova escrita o método de maior incidência.

Portanto, esperamos que o estudo, apesar de suas limitações, possa contribuir com o tema da avaliação formativa no ensino superior, principalmente, em se tratando das áreas de exatas e sociais aplicadas, onde a formação dos professores em bacharelados muitas vezes deixa a desejar em vários aspectos pedagógicos, em especial, na avaliação da aprendizagem.

\section{Referências}

ABRAMOWICZ, Mere; MONIZ, Maria Isabel Dandrade de Souza. Avaliação da aprendizagem em uma perspectiva emancipatória. Nuevamérica, Buenos Aires, n. 125, p. 4447, jan./mar. 2010.

ALVES, Maria Palmir. Currículo e avaliação: uma perspectiva integrada. Porto: Porto, 2004.

BARDIN, Laurence. Análise de conteúdo. São Paulo: Edições 70, 2016.

HADJI, C. Avaliação desmistificada. Porto Alegre: Artmed, 2001.

HOFFMANN, Jussara. Avaliação: mito e desafio - uma perspectiva construtivista. Porto Alegre: Mediação, 1998.

LUCKESI, Cipriano. Avaliação da aprendizagem escolar. São Paulo: Cortez, 2002.

MÉNDEZ, Juan Manuel Álvarez. Avaliar para conhecer, examinar para excluir. Porto Alegre: Artmed Editora, 2002.

MORAES, Dirce Aparecida Foletto. Prova: instrumento avaliativo a serviço da regulação do ensino e da aprendizagem. Estudos em Avaliação Educacional, São Paulo, v. 22, n. 49, p. 233-258, 2011.

PERRENOUD, Philippe. Avaliação: da excelência à regulação das aprendizagens - entre duas lógicas. Porto Alegre: Artmed, 1999.

PERRENOUD, Philippe. Dez novas competências para ensinar: convite à viagem. Porto Alegre: Artmed, 2000.

SAUL, Ana Maria. Referenciais freireanos para a prática da avaliação. Revista de Educação, Campinas, n. 25, p. 17-24, nov. 2008. 
TEIXEIRA, Josele; NUNES, Liliane. Avaliação escolar: da teoria à prática. Rio de Janeiro: Wak, 2008.

TORRE, Saturnino de La. Aprender com os erros: o erro como estratégia de mudança. Porto Alegre: Artmed, 2007.

UNESPAR. Plano político-pedagógico do curso de administração. Paranaguá: Universidade Estadual do Paraná, 2020.

VASCONCELLOS, Celso dos Santos. Avaliação: concepção dialética libertadora do processo de avaliação escolar. 17. ed. São Paulo: Libertad, 2007. 